\title{
REVISTAMARACANAN
}

Dossiê

\section{"Para os ensinar com esse método aos filhos": saberes indígenas e conversão jesuítica junto aos Kiriri nos sertões da América portuguesa (1668-1699)}

\footnotetext{
"To teach them this method to theirr children" Indigenous knowledge and jesuitic conversion among Kiriri nation in the backlands of Portuguese America (1688-1699)
}

Recebido em: 30 abr. 2021.

Aprovado em: 01 out. 2021.

Ane Luise Silva Mecenas Santos*

Universidade Federal do Rio Grande do Norte Natal, Rio Grande do Norte, Brasil

\footnotetext{
* Professora Adjunta do Departamento de História do CERES e do Mestrado em História dos Sertões (MHIST) da Universidade Federal do Rio Grande do Norte. Doutora em História pela Universidade do Vale do Rio dos Sinos. Mestre em História pela Universidade Federal da Paraíba. Especialista em Ciências da Religião e Licenciada e bacharel em História pela Universidade Federal de Sergipe. (anemecenas@gmail.com) 


\title{
Resumo
}

Na segunda metade do século XVII, após a Restauração Portuguesa, intensificou-se o povoamento do sertão da América portuguesa. Coube aos padres da Companhia de Jesus a tutela dos índios da nação Kiriri, que se encontravam na margem sul do Rio São Francisco. Durante esse período de reordenação dos domínios coloniais e de implantação de novos aldeamentos, foi produzido um significativo corpus documental, que versa sobre a solicitação de índios, traz notícias sobre as aldeias, descrições dos espaços e sobre a necessidade da elaboração de novos instrumentos que auxiliassem a comunicação. Para o atendimento destas solicitações, foram realizados estudos linguísticos, com o propósito de sistematizar e normatizar as línguas locais e, assim, tornar possível a comunicação e a pretendida conversão. No presente trabalho, analisamos tanto esta documentação, quanto as duas obras que visaram normatizar a língua Kiriri, o Catecismo da Doutrina Christãa na Lingua Brasilica da Nação Kiriri e a Arte de Grammatica da Lingua Brasilica da naçam Kiriri, escritas pelo padre Ludovico Vicenzo Mamiani Della Rovere e utilizadas nas aldeias de Mirandela, Saco dos Morcegos, Natuba e Geru, na segunda metade do século XVII, com o objetivo de apresentar e de discutir as estratégias de conversão empregadas pelos missionários que atuaram junto aos Kiriri, bem como o processo de tradução cultural que o Catecismo e a Gramática evidenciam.

Palavras-chave: Companhia de Jesus, América portuguesa, Kiriri, Catecismo, Gramática, Ludovico Vicenzo Mamiani.

\begin{abstract}
In the second half of the 17th century, after the Portuguese Restoration, the settlement of the countryside of the Portuguese America was intensified. The tutelage of the Kiriri nation, which was located on the south shore of the São Francisco river, was given to the priests of the Company of Jesus. During this period of reorganization of the colonial domains and beginning of new settlements, an important corpus of documents was produced. These documents tell of natives' pleas, news about the settlements, description of different spaces and the need of elaborating new instruments that could help the communication. In order to answer these pleas, linguistic studies were performed, with the intent of systemazing and creating normatives of the local languages and, thus, make both communication and the desired conversions possible. On this thesis, we analyze both this documentation, as the two works that tried to create a normative for the Kiriri language, the Catecismo da Doutrina Christãa na Lingua Brasilica da Nação Kiriri and the Arte de Grammatica da Lingua Brasilica da naçam Kiriri. Both were written by the priest Ludovico Vicenzo Mamiani Della Rovere and were used in the Mirandela, Saco dos Morcegos, Natuba and Geru settlements during the second half of the 17th century, with the aim of presenting and discussing the conversion strategies employed by the missionaries who worked with the Kiriri, as well as the process of cultural translation that the Catechism and Grammar show.
\end{abstract}

Keywords: Company of Jesus, Portuguese America, Kiriri, Cathecism, Grammar, Ludovico Vicenzo Mamiani. 
Ao lançar o olhar acerca do processo de ocupação da América portuguesa, desde as primeiras tentativas ao longo do século XVI, uma questão foi a tônica do êxito ou insucesso nas constituições de alianças com os povos originários: a habilidade de comunicação. Nas crônicas, cartas e ofícios os portugueses relataram as alianças que as comunidades locais selaram com franceses, neerlandeses, alemães e ingleses. Escambo, articulação dos povos indígenas e narrativas de práticas culturais foram descritas e difundidas, primeiramente, por manuscritos e depois por meio de impressos.

Assim, no período moderno, o "mundo do papel" ganhou cada vez mais importância, por meio também da constante circulação de relatórios administrativos, relatos das experiências e cartas ânuas. Todos esses escritos foram fomentados pelos Impérios ibéricos por meio das práticas de mercê. ${ }^{1}$ Se, por um lado, a publicação em massa possibilitou a difusão de informações em grandes proporções, por outro, os Estados europeus sentiram a necessidade de fiscalizar o acesso ao conhecimento. Assim como a circulação de informação era imprescindível, também a restrição ao acesso se tornou requisito básico na lógica das monarquias católicas. Com isso, havia a necessidade de fiscalização do que era publicado, realizando-se, desse modo, um filtro nas informações transmitidas, como é possível observar na legislação do período. ${ }^{2}$

\footnotetext{
${ }^{1}$ RAMINELI, Ronald. Viagens Ultramarinas. Monarcas, vassalos e governo à distância. São Paulo: Alameda, 2008.

${ }^{2}$ Como é possível observar na legislação do período, das quais destacamos: Ordenações Filipinas, Livro V. São Paulo: Companhia das Letras, 1999, p. 312-313; Alvará de 16 de novembro de 1623. In: Collecção Chronologica da Legislação Portugueza. Compilada e Anotada por José Justino de Andrade Silva. 16201627. Lisboa: Imprensa de F. X. de Souza, 1855, p.106; Carta Régia de 31 de maio de 1632. In: Collecção Chronologica da Legislação Portugueza. Compilada e Anotada por José Justino de Andrade Silva. 16271633. Lisboa: Imprensa de F. X. de Souza, 1855, p. 245; Alvará de 19 de janeiro de 1634. In: Collecção Chronologica da Legislação Portugueza. Compilada e Anotada por José Justino de Andrade Silva. 16271633. Lisboa: Imprensa de F. X. de Souza, 1855, p. 68; Decreto de 18 de outubro de 1651. In.: Collecção Chronologica da Legislação Portugueza. Compilada e Anotada por José Justino de Andrade Silva. 16481656. Lisboa: Imprensa de F. X. de Souza, 1856, p. 88.; Alvará de 6 de julho de 1677. In.: Colleç̧ão Chronologica da Legislação Portugueza. Compilada e Anotada por José Justino de Andrade Silva. Suplemento a Segunda Séria (conclusão) 1675-1683. Lisboa: Imprensa de F. X. de Souza, 1857, p. 167.
} 


\section{Os Kiriri e os espaços de conversão}

Nesse processo no qual foram definidas as obras a serem publicadas, as quais atendiam as normativas portuguesas, alicerçadas aos preceitos que deveriam ser transmitidos aos súditos, é possível identificar a circulação de conhecimento, dos agentes coloniais e o projeto de colonização aplicados.

É nesse cenário de construção de textos atrelados ao processo de conquista, nos deparamos com as narrativas dos religiosos, responsáveis pela administração espiritual dos sacramentos e das políticas temporais de administração. Para esse trabalho, selecionamos os escritos fruto da experiência de conquista dos sertões de dentro da América portuguesa, diretamente relacionados a conversão Kiriri, cuja finalidade é compreender os saberes indígenas traduzidos pelos padres da Companhia de Jesus que atuaram na região. Foram selecionadas dos impressos na construção desse trabalho, escritos pelo padre Vicencio Mamiani della Rouvere ${ }^{3}$ o Catecismo da Doutrina Christãa em Lingua Brasilica da Naçam Kiriri e a Arte de Grammática da Língua Brasilica da Naçam Kiriri

A presença dos missionários da Companhia de Jesus entre os Kiriri é registrada, pela primeira vez, na aldeia de Nossa Senhora da Conceição de Natuba, nos idos de $1666 .{ }^{4}$ Um ano depois, os jesuítas passaram a ocupar a aldeia de Santa Tereza dos Kiriris, em Canabrava. ${ }^{5}$ Em seguida, se fizeram também presentes na aldeia Ascensão do Saco dos Morcegos e Nossa Senhora do Socorro do Geru (1683). ${ }^{6}$ A localização destas aldeias pode ser observada no mapa:

3 Na documentação, padre Mamiani aparece registrado de várias formas, dentre as quais detacamos: Luiz Vicencio Mamiani, Luiz Mamiani, Ludovico Mamiani ou Ludovico Vicenzo Mamiani Della Rovere. O autor da Gramática e do Catecismo escritos na língua Kiriri, nasceu na cidade de Pésaro, na Itália, e passou a integrar a Companhia de Jesus no ano de 1668. Em 1684, antes mesmo de fazer o quarto voto e, contando, então, com trinta e dois anos, partiu de Lisboa, rumo à Bahia. Seu destino inicial na América portuguesa era a Missão do Maranhão. Após consulta à documentação, não foi possível identificar o motivo da mudança do destino do padre Mamiani. O mês de sua chegada não é apresentado nos registros. Contudo, é importante salientar que no começo do ano de 1684, em São Luís, estava ocorrendo o segundo levante contra a atuação dos jesuítas. No primeiro levante, no ano de 1661, o colégio Nossa Senhora da Luz foi invadido e alguns padres foram encaminhados para a Metrópole. Vinte e três anos depois, um novo levante ocorre na cidade, a Revolta de Beckman. Foram apresentados como motivos de insatisfação, a miséria, a cobiça dos padres da Companhia de Jesus e o não atendimento das demandas da população pela Coroa portuguesa. Ver mais em: CHAMBOULEYRON, Rafael. "Justificadas e repetidas queixas. O Maranhão em revolta (século XVII)". In: Actas do Congresso Internacional Espaço Atlântico de Antigo Regime: poderes e sociedades. Disponível em http://cvc.institutocamoes.pt/eaar/coloquio/comunicacoes/rafael_chambouleyron.pdf. Consultado em 16 de setembro de 2015.

4 LEITE, Serafim. História da Companhia de Jesus no Brasil. Tomo V. Rio de Janeiro: Imprensa Nacional. 1945, p. 286.

5 Ibidem, p. 289.

${ }^{6}$ Ibidem, p. 290. 


\section{Figura 1}

BRASIL - ALDEAMENTOS JESUÍTICOS DOS ÍNDIOS KIRIRI -1683

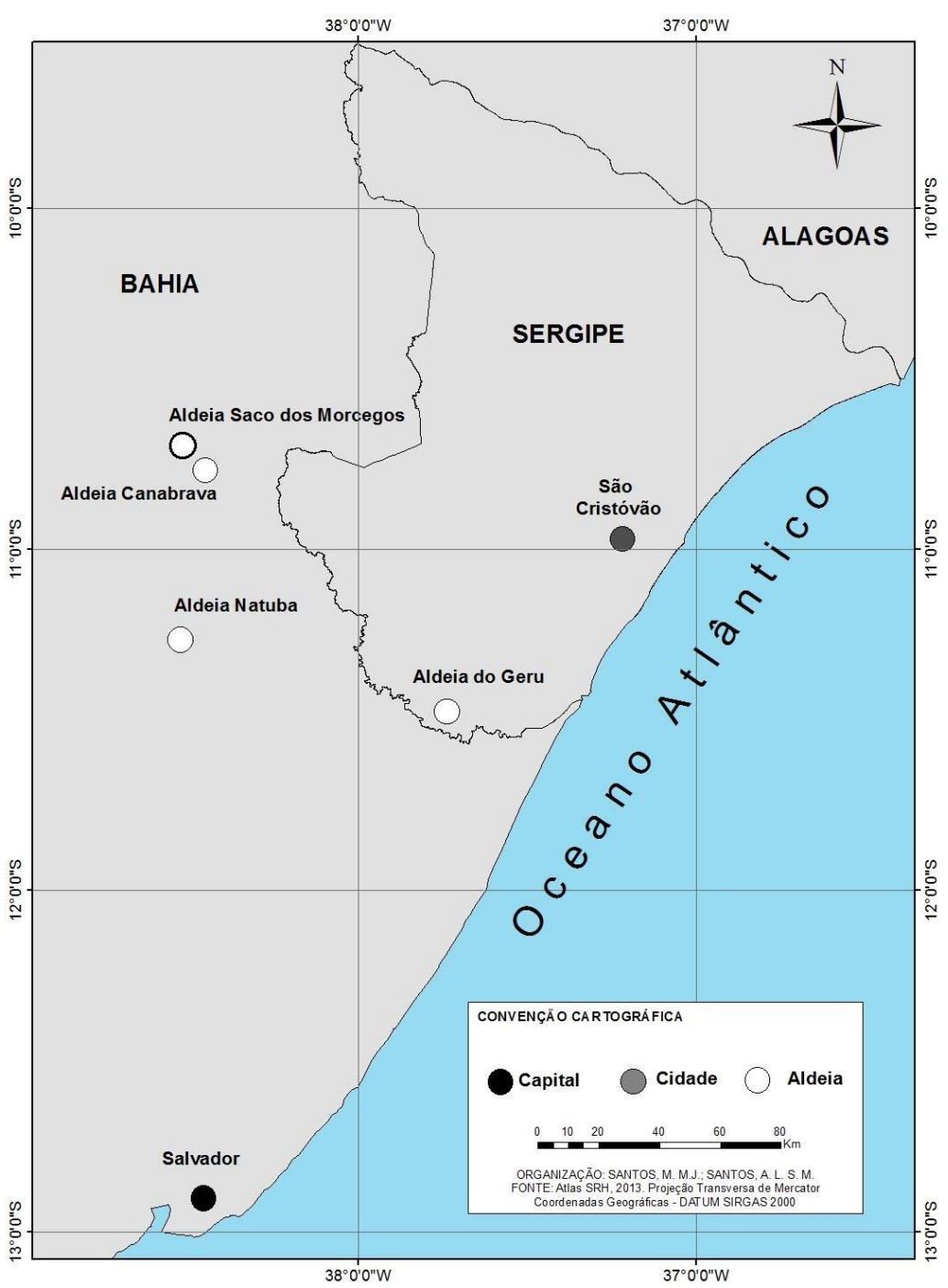

MECENAS, Ane Luise Silva; SANTOS, Marcia Maria de Jesus. Aldeamentos jesuíticos dos índios Kiriri 1683. Atlas SRH, 2013. Projetado Transversa de Marcator, 2017.

Como é possível observar no Mapa, esses aldeamentos estão localizados atualmente no sertão dos estados da Bahia e de Sergipe. Além da particularidade geográfica, essas missões foram instituídas em decorrência da política expansionista de povoamento dos sertões. Desse modo, para compreender as redes institucionais que contribuíram para a formação desses aldeamentos, bem como analisar o papel desempenhado pelos padres da Companhia de Jesus na execução desse processo de povoação e conversão de almas, faz-se necessária a compreensão do contexto de fundação.

A formação das aldeias de Saco dos Morcegos, Natuba, Canabrava e Geru se deu em momentos distintos. Em 1666, os padres da Companhia, João de Barros e Jacob Roland, passaram a defender a importância do trabalho missionário junto às aldeias dos Kiriri, e deste 
empenho resultou a criação das missões das Jacobinas, ${ }^{7}$ dentre as quais estava a de Canabrava. Contudo, em 1667, devido à ação dos criadores de gado da região, estas primeiras missões, com exceção de Canabrava, foram destruídas.

Canabrava foi fundada no contexto das missões das Jacobinas. De todas as missões Kiriri foi aquela em que os jesuítas viveram por mais tempo, até o ano de 1758. Com base nas fontes, viveram na referida aldeia os padres João de Barros, Jacob Roland, Jacques Cocle e José de Araújo. Todos esses missionários sabiam falar algum Kiriri. Sabe-se que esta missão foi também visitada pelo capuchinho Martinho de Nantes e que os índios de Canabrava eram recorrentemente convocados para participar das tropas indígenas. Quanto ao contingente populacional, a localidade possuía 900 almas ao ser elevada à categoria de vila.

Nossa Senhora de Natuba foi fundada em 1666, numa região um pouco mais afastada do sertão da Jacobina. A aldeia foi edificada nas proximidades de um rio perene, o que causava constantes alagamentos, encharcando as áreas destinadas às plantações, dificultando, assim, o plantio e a colheita. Estiveram nessa aldeia os padres Jacob Roland, João Mateus Falleto e Antônio Maria Bonucci. Esse último escreveu a segunda e a terceira parte das Ephemerides Eucharisticas durante o período em que esteve na aldeia. Em 1758, quando da expulsão dos jesuítas, a aldeia contava com 780 índios.

Já a aldeia de Saco dos Morcegos era muito próxima a de Canabrava, mas não era abastecida por riacho ou rio. Em virtude das constantes secas, era comum a fuga dos índios dessa localidade, que, de acordo com os relatos dos padres, viviam metade do ano fora. Havia 960 índios, quando os jesuítas foram afastados desta aldeia.

A última das aldeias Kiriri foi Geru (ou Juru, Geruaçu, Juruaçu). Os jesuítas passaram a ocupar a região após 1683, mediante a compra do terreno dos carmelitas. Consta que lá viveram os padres Luigi Vicencio Mamiani, João Baptista Beagel, Matheus Falleto, Domingos de Matos e o irmão Manuel de Sampaio. Durante sua passagem pela aldeia, o padre Mamiani preparou a publicação da Arte de Língua Kiriri e do Catecismo em mesma língua. O padre Matheus Falleto também se dedicou a escrever e publicar a obra intitulada De Regno Christi in terris consummato.

Nesse espaço de contato a construção de alianças era de fundamental importância nas negociações e na construção de redes de cooperação na América. E para tanto, todos precisavam apresentar, barganhar e defender argumentos que pudessem beneficiar a todos envolvidos no processo. Para isso, a comunicação se tornou um elemento basilar na teia social e fez-se necessário a normalização dos de línguas indígenas.

Dessa forma, os textos do padre Mamiani, tanto a Arte de língua quanto o Catecismo, buscam sistematizar e publicizar as experiências no contato com esse grupo de indígenas. Foi publicada a obra do Catecismo da Doutrina Christãa em Lingua Brasilica da Naçam Kiriri. Na apresentação do Catecismo em português e em Kiriri, sob a forma de um texto bilíngue,

\footnotetext{
7 É o nome dado a região onde as missões se efetivaram no século XVII, fica localizada no sertão do atual estado da Bahia, nas proximidades do município de Jacobina.
} 
favorecia tanto para o missionário que precisava aprender a língua para que pudesse se comunicar com os indígenas, quanto ao indivíduo que pretendia ensinar o catecismo aos seus filhos ou a seus escravizados, indígenas ou africanos, que falavam Kiriri ou português.

Ajuntei neste Catecismo a significação Portugueza correspondente à fraze da língua Kiriri por duas causas. A primeira, para que os novos Missionarios por essa via vendo os exemplos na língua, e o modo de falar, e assim aprender mais depressa a língua. A segunda causa he, porque se acaso este livrinho vier às mãos de quem não sabe a língua Kiriri, se aproveite tambe dele, ou para aprender os mysterios, ou para os ensinar com esse método aos filhos, escravos e outros de sua obrigação. ${ }^{8}$

O texto evidencia a preocupação de Mamiani com a transmissão dos ensinamentos e aponta não apenas para as múltiplas possibilidades de recepção da obra pelos diferentes sujeitos que a ele tinham acesso, mas, também, para o papel desempenhado pelos indígenas na transmissão e sistematização do conhecimento linguístico. Outro aspecto que merece ser também considerado diz respeito aos diferentes atores sociais que circulavam ou conviviam com os indígenas das aldeias, como, por exemplo, os escravizados. Para Russel-Wood, aliás, existe "uma área de intercâmbio que quase não provocou qualquer perturbação na superfície histórica [e é a que diz respeito à interpenetração cultural índio-africana]". ${ }^{9}$ A historiografia cristalizou a interpretação de que o convívio entre esses grupos era controlado pelos jesuítas, todavia, devese pensar que na zona de ocupação dos "caminhos de dentro" o que imperou foi a prática da negociação e o convívio intenso entre os sujeitos, devido à proximidade das aldeias em relação às fazendas. Convém destacar que de acordo com Freire, antes mesmo do aldeamento, os índios do Geru já participavam de incursões com os portugueses para o apresamento de africanos escravizados fugidos e para a procura das minas de prata na Serra de Itabaiana. ${ }^{10}$

Outro indicativo dessa comunicação é observado nas denúncias acerca da proximidade entre as aldeias e as fazendas de gado da região, o que de acordo com os padres permitia um constante contato entre os indivíduos. A proximidade das fazendas do aldeamento de Natuba e a utilização da mão de obra indígena nas lavouras de milho e de outros legumes do "senhorio Gaspar Carvalho da Cunha" aproximavam os índios de situações que os levavam a cometer pecados:

(...) estão bem a vista desta Missão com pouco mais distância que um tiro de espingarda o trato e comércio de seus escravos e escravas com estes índios e índias passando já de demasiado abominável faz parecer um seminário de hereges e ateístas. Pede a Vossa Majestade que para se evitar tanto dano e prejuízo que se demarque terras para a dita Missão com a liberdade de poder ela plantar onde até agora plantava e constar de oitocentas almas pouco mais ou menos por ser

\footnotetext{
8 MAMIANI, Luiz Vincêncio. Catecismo da Doutrina Christãa na Lingua Brasilica da Nação Kiriri. Lisboa: Miguel Deslandes, 1698

9 RUSSEL-WOOD, John. Histórias do Atlântico português. São Paulo: Editora da Unesp, 2014 , p. 291.

10 As incursões às minas foram rejeitadas pela coroa, em 1750, em decorrência da proximidade com o litoral, na tentativa de evitar uma busca desenfreada por minérios e o desaquecimento da produção de Sergipe, principalmente o fornecimento de gado que abastecia a economia da Bahia, conforme aponta RUSSEL-WOOD, A. J. R. O Brasil colonial: o ciclo do ouro, c. 1690-1750. In: BETHEL, Leslie (Org.). América Latina colonial. Trad. Mary A. L. de Barros \& Magda Lopes. São Paulo: Edusp/FUNAG, 1999, p. 475.
} 
mui populosa a dita Missão e quando a Vossa Majestade não seja servido mandar se demarque a dita terra na forma referida aos menos seja servido mandar que o dito Senhorio se retire para outro qualquer sítio dos que possue largando este em que está a Missão, a mesma Missão, a qual com as esmolas que lhe oferecem para isso alguns devotos que tanto se servem dela o pagará pelo mesmo preço por que êle arrematou por menos intolerável comprarem os índios a sua mesma terra do que vivem nela possuída de tal senhorio com tanto incômodo dos seus corpos e perigo de suas almas. ${ }^{11}$

Outro aspecto que podemos inferir acerca dessa comunicação nos sertões, consiste no trabalho de Pedro Dias, jesuíta, tido como "apóstolo dos negros", entrou na Companhia com dezenove anos de idade. ${ }^{12}$ Durante o período em que esteve na Capitania de Pernambuco, a população foi assolada por uma grave epidemia de febre amarela. ${ }^{13} \mathrm{O}$ contato com escravizados angolanos, que desempenhavam as mais diferentes funções como escravizados na capitania, contribuiu para que pudesse escrever a Arte da Língua de Angola, sistematizada no colégio da Bahia, no mesmo período em Mamiani organizou seus estudos linguísticos para publicação. Na carta de 3 de agosto de 1694, Pedro Dias informa que estava elaborando um Vocabulário Português-Angolano. Contudo, não há notícias nem de sua publicação e nem do manuscrito. ${ }^{14}$

No início da segunda metade do século XVII, as terras ao sul do Rio São Francisco se encontravam destruídas devido à longa guerra e para que o projeto de colonização rumo aos "caminhos de dentro" fosse bem-sucedido se tornou fundamental encontrar formas para melhor conhecer a região e, assim, efetivar a ocupação. Neste período, o vale do Rio São Francisco teve seu povoamento intensificado, quer através dos pontos de parada para o descanso das boiadas que rumavam da Bahia para o Piauí, quer através da instalação de fazendas, de aldeamentos indígenas sob a tutela de religiosos e, ainda, pela formação de quilombos. Essa dinâmica de povoamento contribuiu para intensificação das relações entre esses diferentes grupos sociais e para a alteração do cotidiano dos sertões, como também para estruturação dos saberes indígenas pelo prisma dos religiosos.

A análise da política de normatização linguística adotada nos sertões da América portuguesa no final do século XVII pode ser observada pelo corpus documental produzidos pelos jesuítas por catecismos, gramáticas, sermões nesse período utilizados na conversão dos índios. Cotejados com a documentação administrativa, elaborada pelos agentes coloniais, na qual são definidas as ações adotadas para efetivação da conquista e povoamento dos sertões.

\footnotetext{
11 Petição pela qual se pede a Sua Majestade terras para os índios de Natuba. In: Documentos Históricos. Vol. LXIV. Rio de Janeiro: Typ. Baptista de Souza, 1944, p. 65.

12 Em julho de 1641, no Rio de Janeiro, realizou o terceiro e o quarto voto. Ocupou vários cargos no Império português na América, por quatro anos foi Superior em Porto Seguro, em seguida exerceu o cargo de Reitor de Santos, por três anos. Após esse período, foi nomeado Procurador nos Engenhos de Açúcar e, posteriormente, desempenhou o cargo de superior de Olinda por seis anos. Cf. LEITE, Serafim. História da Companhia de Jesus no Brasil. Tomo VIII. São Paulo: Edições Loyola. [1938] 2004., p. 277.

${ }^{13}$ Carta do Padre Pedro Dias, Reitor de Olinda, ao Padre Antônio do Rego, Assistente de Portugal em Roma. 30 de julho de 1689. ARSI, Bras. 9, p. 351-356.

14 Carta do Padre Pedro Dias ao Padre Tiso González, da Bahia, 3 de agosto de 1684. ARSI. Bras. 3(2), p. 337.
} 
Por meio da consulta aos documentos do Arquivo Ultramarino, das cartas ânuas e da coleção Documentos Históricos da Biblioteca Nacional, é possível identificar as diversas solicitações dos agentes coloniais para publicação de obras que facilitassem a comunicação com os povos que habitavam os sertões. O estudo das línguas indígenas do sertão e sua sistematização pelos jesuítas e missionários de outras ordens religiosas vinha ao encontro de uma necessidade apontada pelo Império português nas quais autoridades metropolitanas e coloniais haviam solicitado a produção de vocabulários para que pudessem aprendê-las, facilitando a comunicação. Na documentação, contudo, não há identificação da língua específica que deveria ser produzido, ${ }^{15}$ pois as fontes produzidas pelos setores administrativos do Império português referem-se aos povos pelo nome da aldeia:

porque de todo o bom efeito que nesta matéria houver, me haverei por bem servido com os Portuguezes, é o entende-se a sua língua, dará o Governador Ordem a que se faça dela vocabulário, e se imprima para com maior facilidade se poder aprender, quando não esteja feito, como se ordenou aos Governadores passados. ${ }^{16}$

Mas, para além das regras emanadas do Estado português e da própria ordem, é preciso considerar que foi a experiência na aldeia, atrelada ao longo período de contato com os índios que possibilitou a sistematização das línguas indígenas pelos missionários.

\section{O mundo dos Kiriri e a experiência da conversão}

Ao observar o contexto de produção dos instrumentos linguísticos é possível mensurar o papel desses escritos no projeto de colonização do Império português e suas conexões com as políticas e tentativas de controle dos espaços ocupados pelas populações indígena. A partir do olhar em escala menor, direcionada pela trama narrativa dos padres, evidencia-se as construções imagéticas, as traduções culturais desses povos por meio da pena. E nessa construção simbólica os perigos e inimigos são outros, tolhidos e referenciados pelo prisma religioso, pelos cânones e preceitos divinos de Igreja Católica.

Dentre esses inimigos, podemos destacar a carne, por ser um empecilho na busca por humildade e por dificultar o desapego de si, sendo o mais tenaz deles, pois acolhe as seduções do demônio, através das tentações do corpo, que ferem as leis do espírito. Assim, não para além dos problemas já apresentados e empecilhos a conversão, muitas vezes incutidos aos criadores de gado, escravizados e intérpretes, as ações dos Kiriri se refletem como inimigos. O qual pode se fundamentar transvestido de desespero, na falsa crença de salvação sem merecimento, na

\footnotetext{
15 Cabe ressaltar que somente para os Kiriri, são atribuídas quatro línguas, das quais apenas duas são conhecidos na atualidade.

16 Regimento que trouxe Roque da Costa Barreto, Mestre de campo general do Estado do Brasil. 23 de janeiro de 1677. Correspondências dos Governadores Geraes. Regimento dado ao Governador Roque Barreto Vol. VI da série de IV Documentos Históricos. 1663-1677. Rio de Janeiro: Augusto Porto, 1928, p. 317.
} 
construção de narrativas permeadas pela mentira, na inveja das "mercês que Deos faz a outrem", na permanência pelo pecado ou ainda na impenitência. ${ }^{17}$

Ao escrever quais as práticas se constituem inimigas à salvação, o religioso aponta ações que cotidianamente devem ser combatidas dentro do aldeamento. E assim, descreve comportamentos que deveriam ser evitados, a fim de promover a salvação. Nesse jogo de proibições e normativas Mamiani também descreve hábitos e costumes vivenciados nesse espaço de intercessão de mundos no qual se constitui a aldeia.

Os dias passam a ser definidos a partir da lógica da conversão e a carga do pecado incide pelos quais são o seguem pela lógica do "bom cristão". Os pecados também estão associados a não observância dos dias santos, como, por exemplo, a participação ou realização de festas ou banquetes no período da Quaresma, em flagrante desacordo com o terceiro mandamento, como observado por Mamiani:

M. Qual he o terceiro mandamento da Ley de Deos?

D. Guardarás os domingos, \& as festas.

M. Que havemos de fazer para guardamos este preceito?

D. No Domingo, \& dia Santo não se trabalha na roça; não se levanta, não se cobre a casa, nem se cortão paos no mato; não se coze; não se fia; em sim se deixa todo o trabalho. No Domingo \& dia Santo o que havemos de fazer he ouvir Missa, rezar \& ouvir a pregação do Padre. Tudo isso he melhor do q beberem vinho, \& fazerem seus folguedos. ${ }^{18}$

Não obstante domingos e dias Santos devem ser dedicados a participação no sacrifício da missa, voltado para orações e pelo exercício de ouvir. Deixa se ser um dia para atividades definidas como trabalho, voltado para subsistência do grupo, como práticas agrícolas, de construção de habitações, e, ou o exercício de técnicas manuais, como fiar. Essa é uma habilidade do grupo destacada pela lente do jesuíta que buscava proibir. Também ocorre uma definição de qual calendário festivo deveria ser seguido, numa hierarquização de práticas, das quais as festas definidas no calendário religioso ganham conotação sagrada e as práticas festivas dos Kiriri se apresentavam como folguedos. Na definição de Rafael Bluteau (1728), folguedo se constitui como um passatempo, uma recreação ou um divertimento. Podemos inferir que não consiste apenas uma hierarquização de práticas, mas em não identificar festas religiosas dos indígenas como celebrações.

Ao cotejar o pensamento de Mamiani com outro religioso da localidade encontramos outras descrições acerca dos indígenas durante o período de celebrações. Mais uma vez parte das ações definidoras dos inimigos da salvação. Em 1709, o frei capuchinho Bernardo de Nantes atuava na conversão dos Cariri, 19 nas proximidades do Rio São Francisco. Fruto do seu trabalho missionário

17 MAMIANI, Luiz Vincêncio. Catecismo da Doutrina Christãa na Lingua Brasilica da Nação Kiriri. Lisboa. Edição fac-similar. Rio de Janeiro: Biblioteca Nacional [1698] 1942, p. 13 - 14.

18 Ibidem, p. 87 - 88.

19 Atualmente, são conhecidos como os Kariri-Xokó e habitam o baixo São Francisco, em região que pertence ao munícipio Porto Real do Colégio, no estado de Alagoas. A normatização linguística desse povo foi realizada pelo capuchinho Bernardo de Nantes. 
elaborou e publicou um catecismo. Bernardo de Nantes, alertava para a possível relação entre roubos e a não assistência de alguns índios às missas oficiadas aos domingos:

Padre, os ladrões nos furtão à vezes nossas canoas, alguns se queixão também que Ihes furtão cavalos, \& vacas, levarão também os ladrões canoas, cavalos \& vacas às costas? Não hão de ter força para isto, que a carga sera muito pezada: acho-vos muito embaraçados com vossa pergunta: responde-vos primeiro, que se queries saber quem são esses ladrões, que vos molestão, olhai, \& observai os que os Domingos, \& festas faltão à Missa do dia, \& à pregação do Padre, porque sem duvida ells devem tomar ete tempo que estais à Missa, para irem fazer esses furtos em vossa ausência. ${ }^{20}$

São duas narrativas construídas com a finalidade de explicar para os indígenas a necessidade de seguir o terceiro mandamento da Igreja. Contudo, as experiências locais se fazem presentes na construção do texto, narrativas vividas ao longo da atuação dos padres descritas com o intuito de definir o exemplo por meio de atos e fatos. Para a aldeia de que nos fala o capuchinho, que havia sido construída às margens do Rio São Francisco, era fundamental poder contar com canoas, além de cavalos e vacas, uma realidade bastante distinta daquela das aldeias dos Kiriri, em que os furtos eram de outra natureza, conforme Mamiani:

D. He pecado, quãdo se deseja a fazenda alhea para a furtar a seu dono; ou quando se deseja algua perda da fazenda ao próximo por ódio, ou quando temos enveja ao que possue. Porém não he pecado desejar para si outra fazenda, como aquella, que tem o próximo. ${ }^{21}$

O jogo da materialidade se faz presente para expor os preceitos do sagrado. No entanto nos servem para tentar compreender a construção de saberes e mensurar os processos e as experiências do cotidiano. Em relação aos pecados, o jesuíta italiano elenca três categorias, que são divididas por níveis de gravidade. O primeiro seria o pecado original, com o qual todos nascem e que devia ser remido através do batismo. É bastante singular a explicação dada por Mamiani para justificar o pecado original e para promover a aproximação do gentio com a prática, que remontaria aos conflitos entre índios e portugueses da região:

M. De que modo fomos máos pelo peccado dos nossos Avós?

D. Declararei isso com hum exemplo. O principal dos Indios de Natuba cómeteo hú crime antigamente contra os Brancos matando hum Capitão; então todos os Brancos se deraõ por inimigos dos dos İndios da Natuba, e de todos os Kiriris, por serem todos da mesma Nação do principal criminoso, por isso captivárão todos q poderão préder. Assim obrou Deos comnosco: Peccou Adão nosso pay contra Deos e por isso Deos se deu por offendido não sómente de Adão, mas também de todos os seus descentes. ${ }^{22}$

Esse episódio apresentado no catecismo, havia ocorrido vinte e três anos antes. Na ocasião o capitão-mor Agostinho Pereira Bacellar foi nomeado para reconduzir os índios das aldeias de

\footnotetext{
${ }^{20}$ NANTES, Bernardo de. Catecismo da Lingua Kariris, acrescentado de várias práticas doutrinaes e Moraes, adaptadas ao gentio e capacidade dos Indios do Brasil. Edicção fac-similar. Leipzig, [1709] 1896, p. 292.

21 MAMIANI, Luiz Vincêncio. Catecismo da Doutrina Christãa... Op. cit, p. 98.

22 Ibidem, p. 140 - 141.
} 
Tapecurú-merim, Massacará e Natuba. Este, no entanto, ao chegar em Natuba, foi assassinado pelo principal Cristóvão, incidente que reavivou as disputas entre os criadores de gado e os índios aldeados. ${ }^{23}$

Os governadores do estado do Brasil etc. Porquanto mandando este Governo o Capitão-mor Agostinho Pereira Bacellar a reconduzir os Indios que eram necessários para a jornada do Sertão a que enviamos o Governador da Conquista Estevão Ribeio Bayão Parete as Aldeias do Tapecurú-merim, Massacará, e Natuba, de que é principal um Indio chamado Christovão, reconhendo-se das primeiras alguns Indios, chegando a da Natuba o dito Principal, não quis aceitar a carta que este Governo Ihe escreveu, nem obedecer as ordenes que levava o dito Agostinho Pereira, antes elles o mataram as frechadas atrozmente: e propondo este Governo em Consulta Geral que fez sobre o caso $(\ldots)^{24}$

Após a morte do capitão-mor, foram enviadas tropas para a aldeia de Natuba, com o objetivo de prender os responsáveis por sua morte. As orientações eram de que, caso as ordens não fossem obedecidas e alguém obstruísse a ação, os membros da tropa estavam autorizados a castigar e prender os "insubordinados". Neste caso, a guerra justa deveria ser acionada, 25 sendo o parâmetro legal para a investida contra os índios que haviam cometido grave crime, mesmo sendo aldeados.

O segundo é o pecado mortal, que é o mais grave contra a lei de Deus, e está relacionado com os pecados capitais. ${ }^{26}$ Pode ser praticado por um pensamento, uma palavra ou uma obra ruim. Com esse pecado há a morte da alma e o praticante perde a graça de Deus, sendo que seu castigo é o inferno.

Por fim, o terceiro é o pecado venial, o mais leve dentre eles. A remissão desse pecado é feita por meio da confissão. Para ser perdoado deveria se arrepender, bater as mãos nos peitos, tomar água benta e em seguida rezar as orações. Ao adotar esses passos no intuito de alcançar o perdão seria agraciado com as indulgencias. ${ }^{27} \mathrm{O}$ jesuíta justifica sua orientação embasado no que se encontra definido na obra o Itinerário dos párocos: ${ }^{28}$

Son capaces los Cathecumenos de indulgencias, porque aunque por estar fuera de la Iglesia no se les pueden conceder por via de absolucion, no ay dificuldad en que

\footnotetext{
23 Um novo capítulo das guerras do sertão foi iniciado logo após a morte do capitão-mor Agostinho Pereira Bacellar, que ocorreu dois anos depois do parecer sobre as missões do sertão de Salvador Correia de Sá, para quem "o total remédio" para o controle dos "tapuias do sertão" era o de que vivessem em liberdade no seu lugar de origem, sendo doutrinados pelos religiosos para que não se envolvessem em conflitos. Salvador Correia de Sá sobre a missionação e o povoamento do sertão, incluso em Consulta do Conselho Ultramarino. AHU. Papéis Avulsos, Bahia, caixa 2, doc. 105, 1675.

24 Patente do Posto de Capitão-mor da jornada que se faz às aldeias da Natuba, provido em Domingos Rodrigues de Carvalho. 20 de outubro de 1677. Documentos Históricos 1677-1678. Vol XIII. Rio de Janeiro: Augusto Porto, 1929, p. 17.

${ }^{25}$ Conforme provisão de 10 de setembro de 1611.

26 São sete os pecados capitais, a soberba, avareza, luxúria, ira, gula, inveja e preguiça. Deviam ser combatidos pelas virtudes contrárias, a humildade, liberdade, castidade, paciência, temperança, caridade e diligência nas coisas de Deus. Cf. MAMIANI, Luiz Vincêncio. Op. cit, p. 12-13.

27 MAMIANI, Luiz Vincêncio. Op. cit, p. 146.

28 Encontramos também evidências de que Mamiani teve contato com a obra do padre Alonso de la Peña Montenegro, intitulada Intinerário para parochos de índios en que se tratan las materias más particulares, tocantes á ellos, para su buena administracion. Esse livro teve sete edições entre os séculos XVII e XVIII, a saber, nos anos de 1668, 1678, 1698, 1726, 1730, 1754 e 1771).
} 
se les concedem per modum suffragy, como las concede el Pontifice a las Animas de Purgatorio, que están fuera de su juricion, que son de otro fuero, y assin en esta sentencia podrán los Christianos ayunar, ò rezar por los Cathecumenos, y aplicarles a ellos las indulgencias que se ganan con essas buenas obras, por quien tiene autoridad para concederlas. ${ }^{29}$

Sua prática também tem relação com o pensamento, a palavra ou a alguma obra contra a lei de Deus. Mamiani aponta uma hierarquização dos roubos. Os casos leves contra a lei de Deus seriam furtar uma espiga de milho ou uma abobora. No entanto se o roubo fosse de gado, cavalo ou dinheiro o indígena caiu em tentação e cometeu um pecado grave. E por isso, o perdão era muito mais difícil. ${ }^{30}$

Os roubos também podiam ser ações do diabo, visto que era ele o responsável por privar os indivíduos da capacidade de discernimento. Por isso, a vigilância deveria ser constante, como proposto por Bernardo de Nantes:

S. Gregorio Bispo de Niza [pode ser Nice] entrando hum dia na Igreja vio o diabo, o qual em figura de negrinho tinhoso, andava ao redor dos confessionários: disseIhe o Santo: Que estás cá fazendo, maldito? Respondeu o diabo: Estou agora restituindo a estes penitentes a vergonha do pecado que Ihes furtei, quando elles o estavão cometendo. ${ }^{31}$

E, dependendo da condição em que se encontrava o pecador, nem a confissão podia Ihe ser administrada:

Este he o ardil, Fieis, de que se serve o diabo, para impedir, que o remédio da cõfissão nos não valha, tapando-nos a boca, para que não botemos por ella a peçonha do pecado fora: quando o lobo quer matar a ovelha, primeiro pegalhe na garganta, apertando-a para Ihe tirar o grito, \& o socorro, que por ali lhe poderá vir: isto faz o lobo infernal, quando quer matar hua alma, tiralhe a voz. ${ }^{32}$

Tanto para o capuchinho francês, quanto para o jesuíta italiano, os pecados eram causados pelas seduções do demônio e pela fraqueza e descontrole dos indígenas diante delas, ${ }^{33}$ como ocorria quando furtavam, mentiam e contavam mexericos. ${ }^{34}$

\begin{abstract}
Vinde cá ladrões quem vos ajudou a furtar cavalos, \& vacas? Padre, ninguém, eu só fiz esse furto, foi o diabo que mo meteo na cabeça; bem está, o diabo vos ajudou a furtar vacas, o diabo no dia do Juizo vos ha de ajudar também a levallas: elle vo las ha de amarrar apertadamente nas costas, \& ha de term ão na carga, que vos não caya dos hombros no chão, para vos levar diante de todos com os feixe de vossos pecados ao fogo infernal: Alligabit ea in fasciculos ad comburendum igni, \& notai que este fogo não vos ha de consumer, mas sempre queimar, porque vos não podereis acabar, nem elle se póde apagar: In ignem inextinguibilem. ${ }^{35}$
\end{abstract}

\footnotetext{
costa de Joan-Ant. Huguenta y Compañia, 1678, p. 300.

30 MAMIANI, Luiz Vincêncio. Op. cit, p. 145.

31 NANTES, Bernardo de. Catecismo da Lingua Kariris... Op. cit., p. 322.

32 Idem.

33 MAMIANI, Luiz Vincêncio. Op. cit, p. 13.

34 NANTES, Bernardo de. Op. cit., p. 290.

35 NANTES, Bernardo de. Op. cit, p. 293-294.
}

29 PEÑA MONTENEGRO, Alonso de la. Itinerario para Párrocos de Indios. 2a. edição. En Leon de Francia: A 
É importante ressaltar que os constantes roubos de animais que Bernardo de Nantes nos relata sob uma perspectiva teológica se associam às recorrentes denúncias feitas pelos curraleiros e que culminaram em alguns dos conflitos. No Catecismo de Nantes, no entanto, os roubos são percebidos como uma das inúmeras formas ardilosas de agir do diabo, que, segundo ele, era:

O pay da mentira (...), \& como tal faz tudo o que póde para nos enganar, \& nos induzir ao imitar na sua maldade, a fim de que Deos nos desampare, como o desamparou a elle; $\&$ assim desamparados fiquemos perdidos, \& condenados. Elle anda a pescaria de nosoutros, como vosoutros ides à pescaria do peixe; quando pescais tendes cuidado com o anzol $(\ldots) .{ }^{36}$

Na tentativa de explicar a ação do demônio, o capuchinho a relaciona com práticas cotidianas dos índios:

Desta sorte faz o diabo para nos enganar, \& cativar: a esse fim elle vos deita, \& apresenta o anzol, \& peçonha do pecado, encuberto com a isca, \& gosto do deleite. Os que a modo de peixes, nescios, \& golosos, se chegao a elle, o comem, fartão a fome do seu apetite com a isca do diabo, \& quando cuidão estar satisfeitos, achaose presos, \& agarrados ao inimigo, que os leva para o inferno, aonde os assa, \& coze nas caldeiras infernaes, que sempre servem no gogo; com esta diferença, que o peixe preso logo morre na caldeira que serve, \& em hum instante se lhe acabao as dores; mas os miseráveis pecadores nunca morrerão no fogo infernal, que sempre arte, \& sofrerão tormentos sempiternos. ${ }^{37}$

Mas, além dos constantes roubos praticados pelos índios, havia outra preocupação recorrente: o apego às superstições, tais como o mau olhado, o agouro de animais - ubukerí adjé - e as práticas de cura, todas elas associadas aos "feiticeiros" ou "advinhadores", os bidzamú buré. O próprio termo adotado por Mamiani para se referir a eles nos dá uma ideia de como o jesuíta os percebia: buré, em Kipeiá, significa "mau". Assim, ele estava se referindo a um "feiticeiro mau", que "colocava feitiço nos outros" e que "curava os doentes de palavra".

M. De que cousa mais havemonos de guardar

D. De todas as abusoes dos Feiticeiros; de adivinhar as cousas futuras; de dar crédito a agouros; de botar feitiço para matar o próximo, de dar crédito a sonhos; e de todas as festas supersticiosas. ${ }^{38}$

Segundo o frei Martinho de Nantes, os Kariri acreditavam que as enfermidades eram causadas por feitiços que eram lançados por inimigos ou desafetos e que para combater as doenças era preciso recorrer a contra feitiçaria. As definições quanto o pecado e ao que deveria ser combativo se mescla aos costumes e práticas dos indígenas.

\footnotetext{
36 Ibidem, p. 182.

37 Ibidem, p. 184.

38 MAMIANI, Luiz Vincêncio. Op. cit, p. 85.
} 


\section{Considerações finais}

Ao observar os estudos linguísticos feitos pelos missionários, eles nos revelam informações não apenas sobre sua formação, talentos e percepções, mas, especialmente, sobre as práticas culturais dos grupos indígenas junto aos quais missionavam. Para Pompa, é neste tipo de registro escrito que podemos enxergar as arestas que construíram os "olhares de fronteira", a partir de uma realidade negociada, perpassada pela teologia cristã e pela cosmologia indígena. A análise que fizemos do Catecismo e da Gramática procurou levar em conta justamente estas arestas próprias do processo de tradução cultural, a fim de refletir sobre estes "olhares de fronteira" que o padre Mamiani lançou sobre os Kiriri. 


\section{Referências}

BARROS, Maria Cândida Drumond Mendes. A relação entre manuscritos e impressos em tupi como forma de estudo da política linguística jesuítica no século XVIII na Amazônia. Revista Letras. N 61. Curitiba: Editora UFPR, 2003. p. 125-152.

BARROS, Maria Cândida Drumond Mendes; FONSECA, Vitor Manoel Marques da. Passagens do livro "Itinerário para Párocos de Índios", de Peña Montenegro (1668), em um confessionário jesuítico setecentista da Amazônia. Boletim Museu Paraense Emílio Goeldi. Ciências humanas. [online]. 2010, vol. 5, n. 3, p. 669-679.

CERTEAU, Michel de. A escrita da História. Tradução de Maria de Lourdes Menezes. 2a Ed. Rio de Janeiro: Forense Universitária, 2006.

DAHER, Andrea. A oralidade perdida. Ensaios de história das práticas letradas, Rio de Janeiro: Civilização Brasileira, 2012.

DIAS, Pedro. Arte da Lingua de Angola. Edição Fac-Similar. Rio de Janeiro, [1697] 2006.

FLECK, Eliane Cristina Deckmann. Entre a caridade e a ciência: a prática missionária e científica da Companhia de Jesus (América platina, séculos XVII e XVIII). São Leopoldo: Editora Unisinos, 2015.

FERRAZ, Maria do Socorro. A sociedade colonial em Pernambuco. A conquista dos sertões de dentro e de fora. In: FRAGOSO, João \& GOUVÊA, Maria de Fátima. Brasil Colonial. 1580-1720. Vol. 2. Rio de Janeiro: Civilização Brasileira, 2015.

FRAGOSO, João; GOUVEIA, Maria de Fátima; BICALHO, Maria Fernanda. Uma leitura do Brasil colonial: base da mentalidade e da governabilidade no Império. Penelope. Revista da História e Ciências Sociais, n 23, 2000, p. 67-88.

GRUZINSKI, Serge. Babel no século XVI. A mundialização e Globalização das Línguas. In: THOMAS, Werner; STOLS, Eddy; KANTOR, Iris, FURTADO, Júnia (org.). Um mundo sobre papel. Livros, Gravuras e Impressos Flamengos nos Impérios Português e Espanhol (século XVI- XVIII). Belo Horizonte: Editora UFMG, 2014. p.385-399.

HARTOG, François. Memória de Ulisses: narrativas sobre a fronteira na Grécia antiga. Trad. Jacyntho Lins Brandão. Belo Horizonte: Editora UFMG, 2004.

LEITE, Serafim. História da Companhia de Jesus no Brasil. Tomo I a X. Rio de Janeiro: Civilização Brasileira, Lisboa: Livraria Portugália. 1938.

LEITE, Serafim. História da Companhia de Jesus no Brasil. Tomo VIII. São Paulo: Edições Loyola. [1938] 2004.

LEITE, Yonne. A arte de gramática da língua mais usada na costa do Brasil e as línguas indígenas brasileiras. In: FREIRE, José Ribamar Bessa Freire; ROSA, Maria Carlota. Línguas Gerais. Política Linguística e Catequese na América do Sul no período colonial. Rio de Janeiro: Editora UERJ, 2003. p.11-24.

LIMA, Ivana Stolze. Na Bahia, a arte da língua de Angola. Comunidades linguísticas no mundo Atlântico. Anais do XXVII Simpósio Nacional de História. Conhecimento Histórico e Diálogo 
Social. Natal, 2013, p. 1-13. Consultado em 14 de fevereiro de 2014. Disponível em: http://snh2013.anpuh.org/resources/anais/27/1371346755_ARQUIVO_ArtigoAnpuh2013.pdf MALDAVSKY, Aliocha. Vocaciones inciertas. Missión y missioneiros en la Provincia Jesuita del Peru. Lima: Universidad Antonio Ruiz de Montoya, 2013.

MAMIANI, Luiz Vincêncio. Catecismo da Doutrina Christãa na Lingua Brasilica da Nação Kiriri. Lisboa: Miguel Deslandes, 1698.

MAMIANI, Luiz Vincêncio. Arte de Grammatica da Lingua Brasilica da naçam Kiriri. Lisboa: Miguel Deslandes, 1699.

MAMIANI, Luiz Vincêncio. Arte de Grammatica da Lingua Brasilica da naçam Kiriri. 2. ed. Rio de Janeiro: Biblioteca Nacional, [1699]1877.

MAMIANI, Luiz Vincêncio. Catecismo da Doutrina Christãa na Lingua Brasilica da Nação Kiriri. Lisboa. Edição fac-similar. Rio de Janeiro: Biblioteca Nacional, [1698] 1942.

MECENAS-SANTOS, Ane Luíse Silva. O trato da perpétua tormenta: a conversão Kiriri nos sertões de dentro da América portuguesa. Edise: Aracaju, 2020.

MARIANI, Bethania. Colonização linguística. Línguas, política e religião no Brasil (século XVI a XVIII) e nos Estados Unidos da América (século XVIII). Campinas, SP: Pontes, 2004.

NANTES, Bernardo de. Catecismo da Lingua Kariris, acrescentado de várias práticas doutrinaes e Moraes, adaptadas ao gentio e capacidade dos Indios do Brasil. Edicção fac-similar. Leipzig, [1709] 1896.

NANTES, Martinho. Relação de uma missão no Rio São Francisco. Brasiliana. Volume 368. Tradução e comentários de Barbosa Lima Sobrinho. 2 ed. São Paulo: Editora Nacional, [1706] 1979.

NUNES, José Horta. Dicionários no Brasil: Análise e História do século XVI ao XIX. Campinas: Pontes, 2006.

PEÑA MONTENEGRO, Alonso de la. Itinerario para Párrocos de Indios. 2a. edição. En Leon de Francia: A costa de Joan-Ant. Huguenta y Compañia, 1678.

POMPA, Cristina. Religião como tradução: missionários, Tupi e "Tapuia" no Brasil colonial. Bauru: EDUSC, 2003.

POMPA, Cristina. Por uma antropologia histórica das missões. IN: MONTEIRO, Paula. Deus na aldeia. Missionários, índios e mediação cultural. São Paulo, Editora Globo, 2006.

PUNTONI, Pedro. A Guerra dos Bárbaros: povos indígenas e a colonização do sertão nordeste do Brasil (1650-1720). São Paulo: Hucitec, 2002.

RAMINELI, Ronald. Viagens Ultramarinas. Monarcas, vassalos e governo à distância. São Paulo: Alameda, 2008.

RODRIGUES, Aryon Dall'igna. Línguas brasileiras: para o conhecimento das línguas indígenas. São Paulo: Edições Loyola, 1986.

RODRIGUES, Aryon Dall'igna. Notas sobre o sistema de parentesco dos índios Kiriri. Revista do Museu Paulista. 1948, p. 193-205.

RUSSEL-WOOD, John. Histórias do Atlântico português. São Paulo: Editora da Unesp, 2014. 
RUSSEL-WOOD, A. J. R. O Brasil colonial: o ciclo do ouro, c. 1690-1750. In: BETHEL, Leslie (Org.). América Latina colonial. Trad. Mary A. L. de Barros \& Magda Lopes. São Paulo: Edusp/FUNAG, 1999.

VALLE, Ivonne del. Escribiendo desde los márgenes: colonialismo y jesuítas en el siglo XVII. México: Siglo XXI, 2009.

VIEIRA, Antônio, SJ. Cartas do Padre Antônio Vieira. Org. João Lúcio de Azevedo. Coimbra, 19251928,3 volumes.

ZERON, Carlos. Da farsa à tragédia: A guerra de facções que pôs fim às esperanças de Antônio Vieira por um Quinto Império e transformou o modo de atuação dos jesuítas do Brasil. In: GALDEANO, Carla; ARTONI, Larissa Maia; AZEVEDO, Silvia Maria (org.). Bicentenário da Restauração da Companhia de Jesus (1814-2014). São Paulo: Loyola, 2014. p. 167-198.

WILDE, Guillermo. Saberes de la conversión. Jesuitas, indígenas e impérios coloniales en las fronteras de la cristiandad. Buenos Aires: SB, 2011. 